\title{
Baseline selection for evaluation of peri-implant soft tissue changes: a clinical trial
}

\author{
Chaoling Zheng ${ }^{1,2}$, Shimin Wang ${ }^{1,2}$, Hongqiang Ye ${ }^{1,2}$, Yunsong Liu ${ }^{1,2}$, Wenjie Hu ${ }^{3}$, Yongsheng Zhou ${ }^{1,2}$ \\ ${ }^{1}$ Department of Prosthodontics, Peking University School and Hospital of Stomatology, Beijing, China; ${ }^{2}$ National Laboratory for Digital and \\ Material Technology of Stomatology, National Clinical Research Center for Oral Diseases, Beijing Key Laboratory of Digital Stomatology, Beijing, \\ China; ${ }^{3}$ Department of Periodontics, Peking University School and Hospital of Stomatology, Beijing, China \\ Contributions: (I) Conception and design: Y Liu, W Hu; (II) Administrative support: Y Zhou; (III) Provision of study materials or patients: C Zheng, \\ S Wang; (IV) Collection and assembly of data: C Zheng, H Ye; (V) Data analysis and interpretation: C Zheng; (VI) Manuscript writing: All authors; \\ (VII) Final approval of manuscript: All authors. \\ Correspondence to: Yunsong Liu. Department of Prosthodontics, Peking University School and Hospital of Stomatology, 22 Zhong Guan Cun South \\ Avenue, Beijing 100081, China. Email: liuyunsong@hsc.pku.edu.cn; Wenjie Hu. Department of Periodontics, Peking University School and Hospital \\ of Stomatology, 22 Zhong Guan Cun South Avenue, Beijing 100081, China. Email: huwenjie@pkuss.bjmu.edu.cn.
}

Background: To select the optimal baseline for evaluation of peri-implant soft tissue changes among 1, 2, and 3 weeks after definitive crown insertion.

Methods: A total of 22 individuals who required implant restoration were recruited to this study. Each participant received a screw-retained conventional implant restoration. Peri-implant soft tissue was captured by an intraoral scanner and analyzed by 3D analysis software. Soft tissue changes [mucosal margin (MM) and soft tissue thickness (STT)] on the buccal side of implant sites were evaluated at 1, 2, and 3 weeks after definitive crown insertion. One-way analysis of variance (ANOVA) for repeated measurement and Tukey's test were used to analyze significant differences between the 3 time points $(\alpha=0.05)$.

Results: An increased volume of peri-implant soft tissue was observed shortly after definitive crown insertion. Based on the findings of peri-implant soft tissue changes, significant differences were observed between weeks 1 and $2(\mathrm{P}<0.01)$, and weeks 1 and $3(\mathrm{P}<0.01)$, while there was no significant difference between weeks 2 and $3(\mathrm{P}>0.05)$.

Conclusions: Minimal peri-implant soft tissue changes occurred in this study. The time point of 2 weeks after definitive crown insertion was preliminarily selected as the baseline. The small sample size and few time points must be taken into consideration when interpreting these findings.

Trial Registration: This study was retrospectively registered in the Chinese Clinical Trial Registry (Registration number: ChiCTR2000037954; Date of registration: 6 September 2020).

Keywords: Baseline selection; definitive crown insertion; peri-implant soft tissue changes; evaluation

Submitted Jun 29, 2021. Accepted for publication Aug 30, 2021.

doi: 10.21037/atm-21-3335

View this article at: https://dx.doi.org/10.21037/atm-21-3335

\section{Introduction}

Recently, with the wide use of implant restoration, many researchers have closely observed the pattern of periimplant soft tissue changes after definitive crown insertion
(1-4). Several studies have investigated the patterns of change (3-5); however, the baselines among them have been inconsistent.

In 2011, Schneider et al. performed autogenous subepithelial connective tissue graft (SCTG) 6 months after

\footnotetext{
^ ORCID: 0000-0001-8364-1898.
} 
guided bone regeneration (GBR) with simultaneous implant placement and evaluated peri-implant soft tissue changes within 1 year, applying a baseline of 1 week after definitive crown insertion (6). In 2017, Bienz et al. performed implant placement simultaneously with or without SCTG after GBR and evaluated peri-implant soft tissue changes within 5 years with the baseline of 1 week after definitive crown insertion (5). In 2018, Huber et al. compared the effect of 2 soft tissue augmentations, xenogenous three-dimensionally (3D) stable collagen matrix (VCMX) and SCTG, with a follow-up period of 1 year and baseline of 2 weeks after definitive crown insertion (4). In 2020, Thoma et al. compared the above 2 soft tissue augmentations of VCMX and SCTG with 3 years follow-up duration and baseline of 2 weeks after definitive crown insertion (3). These previous studies obtained the intraoral digital information by model scanner and did not explain the reason why they select these time points as baseline (1 or 2 weeks).

The results of soft tissue thickness (STT) changes were different between Schneider et al. (-0.02 mm) (6) and Huber et al. $(-0.20 \mathrm{~mm})$ (4), which may have been due to the different baselines ( 1 or 2 weeks). To date, studies investigating baseline selection have been scarce.

The objective of this study was to determine the optimum baseline for evaluation of peri-implant soft tissue changes among 1,2, and 3 weeks after definitive crown insertion.

We present the following article in accordance with the Transparent Reporting of Evaluations with Nonrandomized Designs (TREND) reporting checklist (available at https:// dx.doi.org/10.21037/atm-21-3335).

\section{Methods}

\section{Study design and setting}

Baseline selection for evaluation of peri-implant soft tissue changes was the goal of this clinical trial. Peri-implant soft tissue changes were evaluated using digital method at 1 , 2 , and 3 weeks after definitive crown insertion. The study protocol was carried out in accordance with the Declaration of Helsinki (as revised in 2013) and was approved by the Biomedical Ethics Committee of Peking University School and Hospital of Stomatology, Beijing, China (ethical batch number: PKUSSIRB-201946083). The dentist who enrolled the participants and the investigator who evaluated peri-implant soft tissue changes were blinded to the study protocol and purpose.
The sample size was calculated in PASS (Power Analytics and Sample Size Software, NCSS, LLC, Kaysville, UT, USA) software ( $\alpha=0.05,80 \%$ power) according to the $\triangle \mathrm{AMM}$ data (the first 3 patients recruited) of this study. After calculating, a study population of at least 20 participants was necessary. Considering a dropout rate of $10 \%$, a total of 24 patients were recruited.

\section{Participants}

The study was carried out in the Department of Periodontology and Prosthodontics, Peking University School and Hospital of Stomatology, from October 2018 to February 2020. All patients signed consent forms prior to participation. Continuous patients who required implant restoration were recruited according to the following inclusion criteria: (I) age $\geq 20$ years old (7); (II) no systemic disease or active periodontitis; (III) plaque index and bleeding index $<25 \%$ (8); (IV) posterior tooth loss with a medium to thick gingival biotype (periodontal probe not visible when inserted into the buccal gingival margin) (9); and (V) fully autonomous behavior and expression ability, with good compliance. Exclusion criteria were as follows: (I) poor oral hygiene; (II) adjacent teeth with acute and chronic tooth disease at the implant site; (III) uncontrolled diabetes or other systemic disease; and (IV) heavy smoker $(\geq 10$ cigarettes/day). In addition, implants were excluded if they manifested complications during the period of this study that required additional treatments. The dentist responsible for participant recruitment was blinded to the study protocol and purpose.

\section{Surgical procedures}

Systematic supportive periodontal therapy before surgery was executed for all participants, and the clinical treatment plans were discussed and agreed upon prior to implantation. A timeline of the clinical treatment process is shown in Figure 1. The two-stage implant was placed according to the manufacturer's instructions (Bone Level, Straumann ${ }^{\circledR}$, Basel, Switzerland) under local anesthesia. A healing abutment was inserted 6 months later followed by a definitive all-ceramic zirconia crown (titanium abutment) 3 months after the second-stage procedure.

\section{Clinical examination}

All participants received oral prophylaxis. An evaluator 


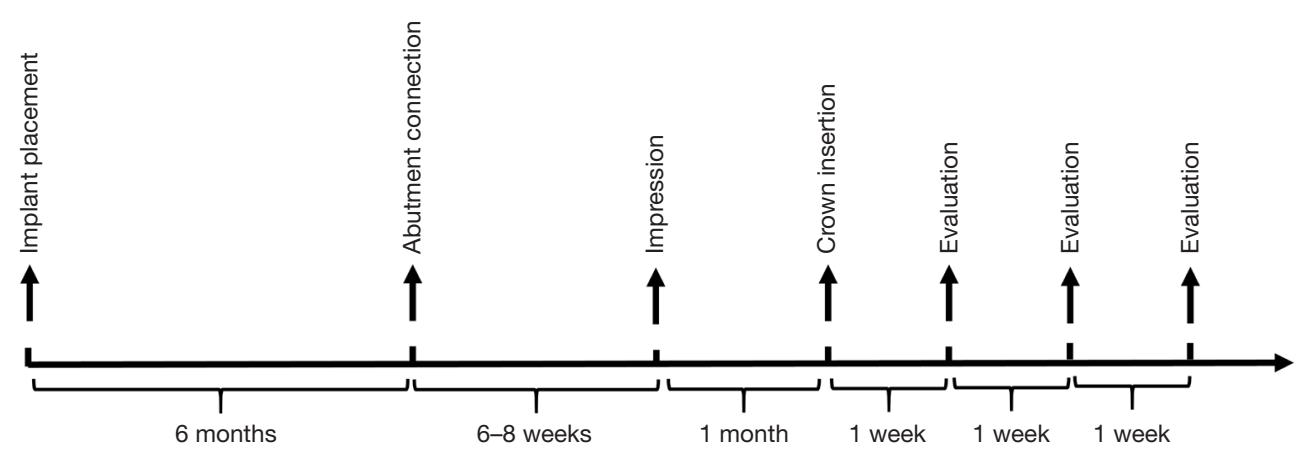

Figure 1 Timeline of the clinical treatment process.

recorded the following indicators 3 times, which were then averaged. Values were recorded at mesial, midfacial, distal, and palatal sites and then averaged. The gingival index (GI) (10) and bleeding on probing (BOP, positive or negative; \%) (11) were recorded after probing (Williams, Hu-Friedy, Chicago, IL, USA). The GI and BOP are commonly used to determine whether there is inflammation surrounding an implant (12).

\section{Peri-implant soft tissue evaluations}

All measurements were carried out by 1 evaluator. The following indicators were recorded 3 times and then averaged. The investigator who evaluated peri-implant soft tissue changes was blinded to the study protocol and purpose.

\section{Intraoral scanning}

First, 3D oral information was captured by an intraoral scanner (TRIOS Color Pod; software version: 1.18.1.3, 3Shape, Copenhagen, Denmark) at each time point. All scanning data were saved in DCM (a software-dedicated file format) format. Then, the digital files were imported into orthodontic software (Ortho Analyzer ${ }^{\mathrm{TM}}$, software version: 1.18.1.2, 3Shape, Denmark) and saved as a virtual reality modeling language (VRML) file. After the file format transform process, a color digital model (colored by VRML procedure) was obtained and imported into $3 \mathrm{D}$ analysis software (Geomagic Control 2014, 3D Systems, Rock Hill, SC, USA) to evaluate the peri-implant soft tissue changes.

\section{Digital model alignment}

In the Geomagic Control software, the scanning data obtained immediately after crown insertion was set as the reference model and the follow-up scanning data as the test model, then "best fit alignment" (iterative closet point algorithm) was conducted (Figure 2A). According to the accuracy of the intraoral scanner, maximum and minimum nominal values were set at 150 and $-150 \mu \mathrm{m}$, respectively (2). The area of interest on the buccal side was then selected, with the coronal border represented by the mucosal margin $(\mathrm{MM})$, the apical border by the vestibular groove, and the mesial and distal border by the axis angle. Directions of $\mathrm{X}$-axis, $\mathrm{Y}$-axis, and $\mathrm{Z}$-axis are shown in Figure 2B,2C. Root mean square (RMS) was recorded after alignment. The RMS of the test model compared to the reference model was used to estimate the congruency of two superimposed records $(13,14)$ by the formula $(15)$ :

$$
R M S=\sqrt{\frac{\sum_{i=1}^{n} X_{1, i}^{2}-X_{2, i}^{2}}{n}}
$$

where $X_{1, i}$ is measuring point $i$ on test model, $X_{2, i}$ is measuring point $i$ on reference model, and $n$ is the total number of measuring points per model.

\section{Analysis of changes in mucosal margin ( $\triangle \mathrm{AMM})$}

First, the "insertion point" function was used to select gingival zenith at mesial, midfacial, and distal sites of the buccal side. Then, the 3D coordinates at the 3 sites were recorded (Figure 2D). The difference between the $\mathrm{Z}$-axis coordinates in the reference and test models was represented as the changes in the MM. Changes at the 3 sites were then averaged $(\triangle A M M)$. Negative values represented the mucosal recession.

\section{Analysis of changes in STT}

The changes in STT at 1, 3, and $5 \mathrm{~mm}$ below the MM were analyzed (16). First, "2D comparison" function was used to generate $2 \mathrm{D}$ cross sections at mesial, midfacial, and distal 

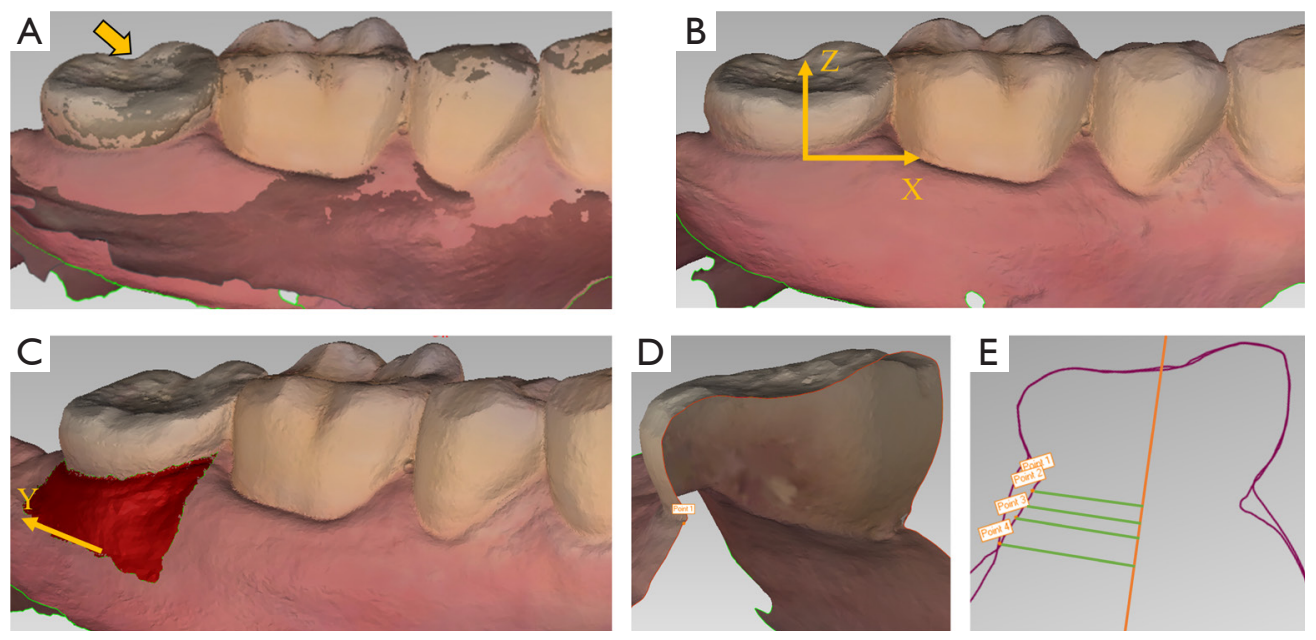

Figure 2 Digital analysis. (A) Best fit alignment; (B) direction of X-axis and Z-axis; (C) direction of Y-axis; (D) analysis of changes in mucosal margin; (E) analysis of changes in soft tissue thickness. The arrow in (A) indicates implant restoration. The arrows in (B) indicate directions of $\mathrm{X}$ and $\mathrm{Z}$ axis respectively. The arrow in $(\mathrm{C})$ indicates direction of $\mathrm{Y}$ axis.

sites of the buccal side respectively (Figure 2E). To evaluate STT at each level, longitudinal lines were drawn parallel to the long axis of the implant in each $2 \mathrm{D}$ section. Distances at each level between the reference model and test model were then used to represent the changes in STT. Changes at the 3 sites were then averaged ( $\triangle$ ASTT). Negative values represented soft tissue collapse.

\section{Statistical analysis}

The participant was treated as the unit of statistical analysis (every participant with a single implant). Descriptive statistics [mean \pm standard deviation (SD)], normality (Kolmogorov-Smirnov test), and homogeneity of variance (Levene test) were performed for all variables (repeated measurement data) using SPSS software $\left(\mathrm{IBM}^{\circledR}\right.$, SPSS $^{\circledR}$, Statistics 20, Chicago, IL, USA). The one-way analysis of variance (ANOVA) was used to analyze $\triangle \mathrm{AMM}$ and $\triangle \mathrm{ASTT}$ among the 3 time points. If proven to be statistically significant, Tukey's test was used to perform multiple comparison. The Friedman test was used to compare GI and BOP among the 3 time points. A P value $<0.05$ was considered statistically significant.

\section{Results}

\section{Participant and implant characteristics}

A flow diagram of the recruitment process is shown in Figure 3. Of the 24 patients (24 posterior implants) enrolled, 2 did not complete the follow-up due to study abroad or having no discomfort A total of 22 participants (22 implants) were therefore included in this study, 11 females (11 implants, 3 in maxilla and 8 in mandible) and 11 males (11 implants, 9 in maxilla and 2 in mandible), with an average age of 53.0 \pm 8.8 years (34-73 years). Table 1 shows the detailed participant characteristics.

\section{Clinical outcomes}

Table 2 shows the clinical outcomes. The mean GI values were $0.89 \pm 0.28,0.79 \pm 0.30$, and $0.88 \pm 0.33$ at 1,2 , and 3 weeks, respectively. The mean BOP values were $11.36 \pm 12.74,12.50 \pm 14.94$, and $10.23 \pm 14.76$ at 1,2 , and 3 weeks, respectively. There was no significant difference among the 3 time points (GI: $\mathrm{P}=0.234$; BOP: $\mathrm{P}=0.695$ ). After initial therapy, peri-implant soft tissue was in healthy status.

\section{Peri-implant soft tissue evaluations}

The mean RMS values were $27.24 \pm 11.61,28.78 \pm 11.69$, and $25.75 \pm 11.41 \mu \mathrm{m}$ at 1,2 , and 3 weeks, respectively (Table 2).

The $\triangle \mathrm{AMM}$ and $\triangle \mathrm{ASTT}$ values at 1,2 , and 3 weeks after baseline are shown in Table 3. Table 4 shows the oneway ANOVA results. Based on the findings of peri-implant soft tissue changes, significant differences were observed between weeks 1 and $2(\mathrm{P}<0.001)$, and weeks 1 and 3 $(\mathrm{P}<0.01)$, while there was no significant difference between 


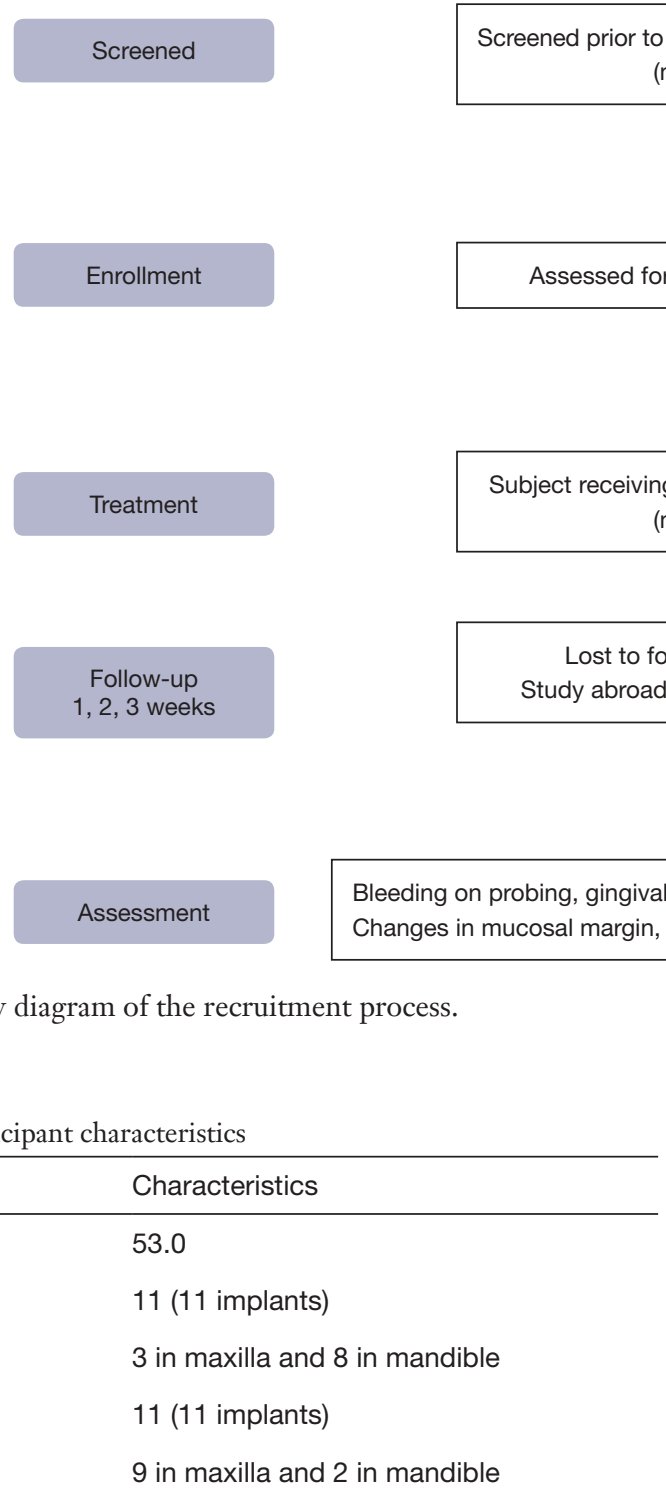

Table 2 Results of GI, BOP, and RMS

\begin{tabular}{lcccc}
\hline Parameters & $1 \mathrm{w}$ & $2 \mathrm{w}$ & $3 \mathrm{w}$ & $\mathrm{P}^{\mathrm{a}}$ \\
\hline Gl, mean \pm SD & $0.89 \pm 0.28$ & $0.79 \pm 0.30$ & $0.88 \pm 0.33$ & 0.234 \\
BOP $(\%)$, & $11.36 \pm 12.74$ & $12.50 \pm 14.94$ & $10.23 \pm 14.76$ & 0.695 \\
mean \pm SD & & & & \\
RMS $(\mu \mathrm{m})$, & $27.24 \pm 11.61$ & $28.78 \pm 11.69$ & $25.75 \pm 11.41$ & - \\
mean \pm SD & & & & \\
\hline
\end{tabular}

1 w, 2 w, and 3 w: 1 week, 2 weeks, and 3 weeks after definitive crown insertion respectively. ${ }^{a}$, results of Friedman test. GI, gingival index; BOP, bleeding on probing; RMS, root mean square; SD, standard deviation.
Table 3 Descriptive statistics (mean \pm SD, $\mathrm{mm}$ ) of changes in periimplant soft tissue

\begin{tabular}{lccc}
\hline Parameters & $1 \mathrm{w}$ & $2 \mathrm{w}$ & $3 \mathrm{w}$ \\
\hline$\Delta \mathrm{AMM}$ & $0.13 \pm 0.07$ & $0.03 \pm 0.09$ & $0.02 \pm 0.10$ \\
$\Delta \mathrm{ASTT}_{-1 \mathrm{~mm}}$ & $0.20 \pm 0.04$ & $0.04 \pm 0.05$ & $0.03 \pm 0.06$ \\
$\Delta \mathrm{ASTT}_{-3 \mathrm{~mm}}$ & $0.14 \pm 0.08$ & $0.03 \pm 0.08$ & $0.03 \pm 0.07$ \\
ASTT $_{-5 \mathrm{~mm}}$ & $0.13 \pm 0.05$ & $0.02 \pm 0.06$ & $0.02 \pm 0.07$ \\
\hline
\end{tabular}

$1 \mathrm{w}, 2 \mathrm{w}$, and $3 \mathrm{w}$ : 1 week, 2 weeks, and 3 weeks after definitive crown insertion respectively; $S D$, standard deviation; $\triangle A M M$, changes in mucosal margin; $\triangle \mathrm{ASTT}$, changes in soft tissue thickness.

weeks 2 and $3(\mathrm{P}>0.05)$. The soft tissue changes became relatively stable 2 weeks after definitive crown insertion (Figure 4). The time point of 2 weeks after definitive crown insertion was therefore preliminarily selected as the baseline.

\section{Discussion}

In this study, peri-implant soft tissue contour was captured 
Table 4 One-way ANOVA results

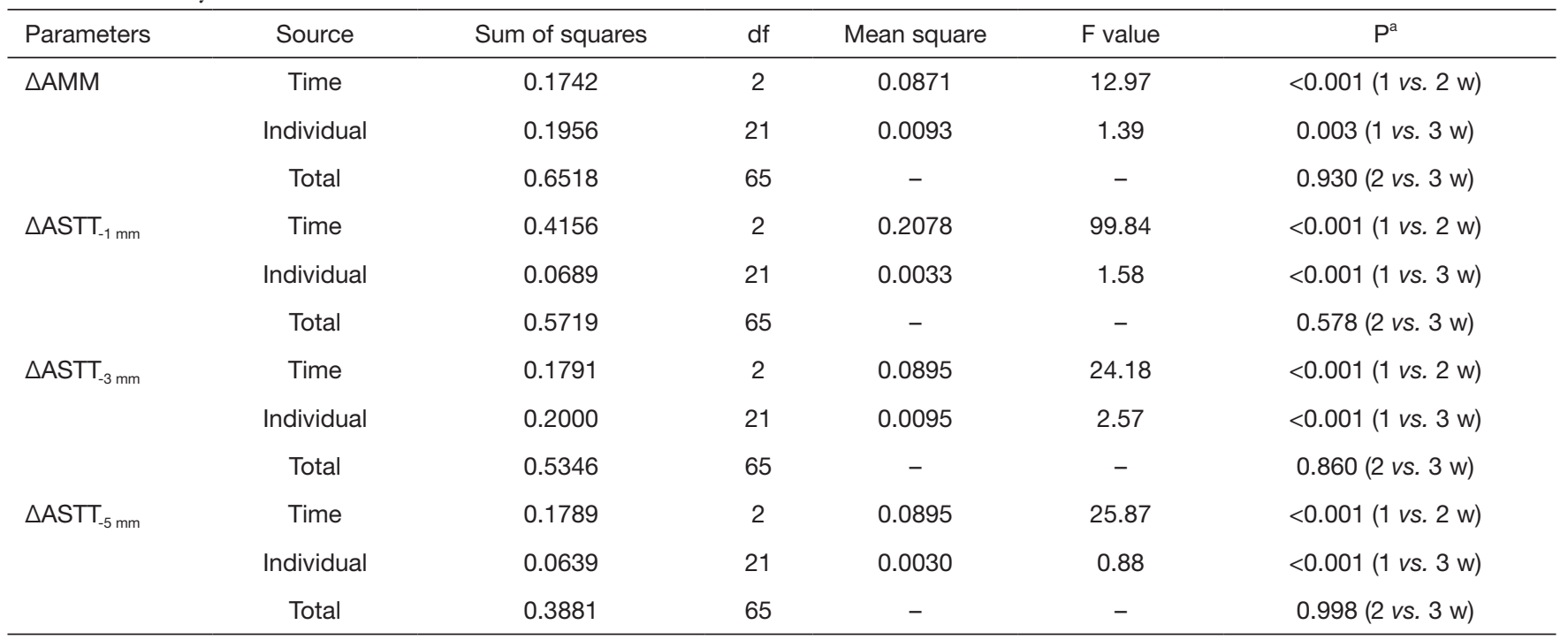

${ }^{a}$, results of Tukey test. df, degrees of freedom; ANOVA, analysis of variance; $\triangle \mathrm{AMM}$, changes in mucosal margin; $\triangle \mathrm{ASTT}$, changes in soft tissue thickness.
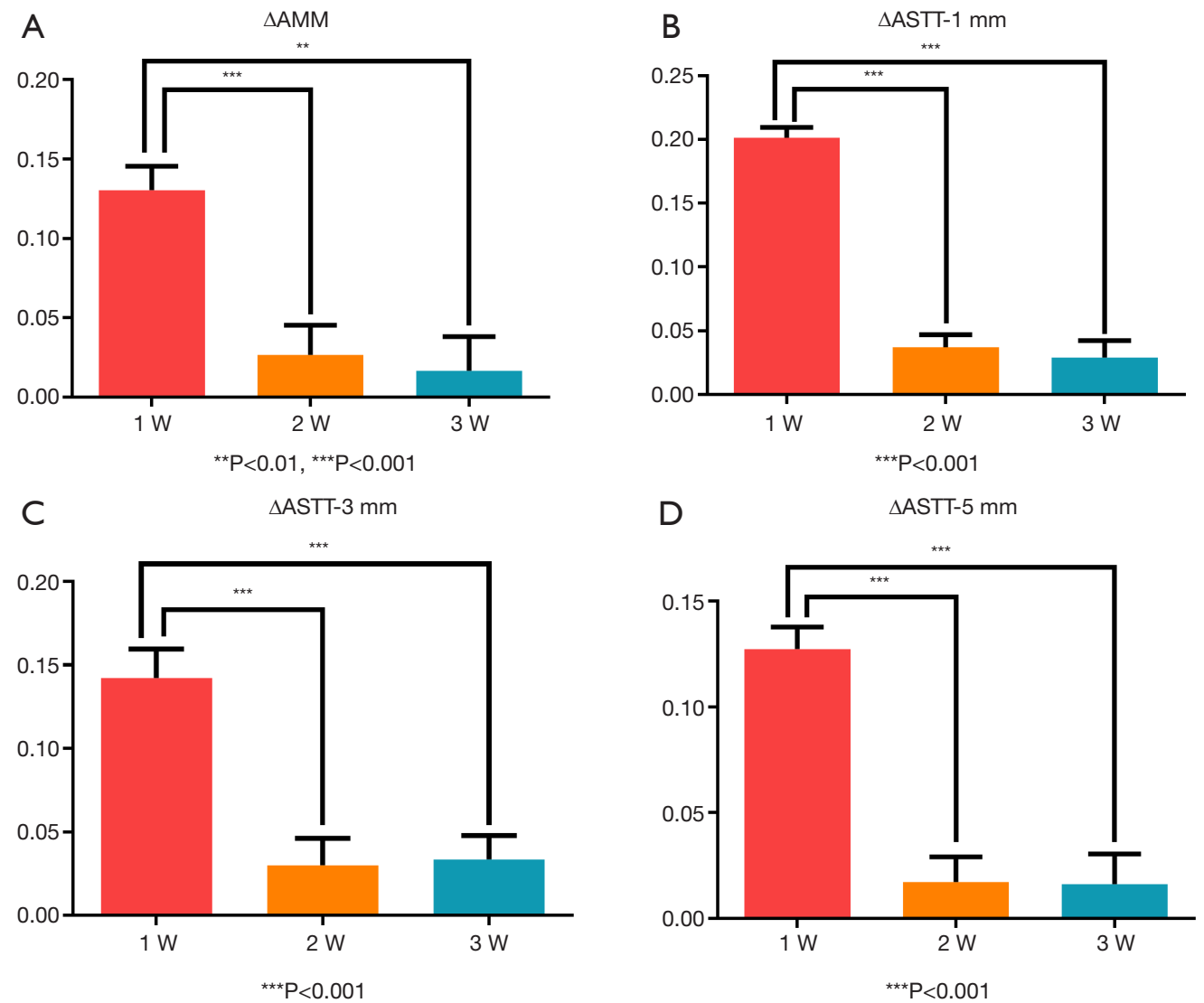

Figure 4 Analysis for baseline selection. (A) Result of $\triangle \mathrm{AMM}$ among the 3 time points; (B-D) result of $\triangle \mathrm{ASTT}$ among the three time points. $1 \mathrm{w}, 2 \mathrm{w}$, and $3 \mathrm{w}, 1$ week, 2 weeks, and 3 weeks after definitive crown insertion respectively; $\triangle \mathrm{AMM}$, changes in mucosal margin; $\Delta$ ASTT, changes in soft tissue thickness. 
by a 3 Shape intraoral scanner which is reportedly noninvasive (17) and superior in terms of precision $(18,19)$, and changes of soft tissue (MM and STT) were evaluated using digital method. In 2019, Fageeh et al. compared the precision for evaluating gingival recession among 4 methods [periodontal probe, digital vernier calipers, and digital methods (soft tissue was obtained by 3 Shape intraoral scanner or 3Shape model scanner)] (20). The results showed that digital methods (soft tissue was obtained by 3 Shape intraoral scanner) were superior in terms of precision (20). The results of this study showed that the soft tissue changes become relatively stable 2 weeks after definitive crown insertion.

It has been reported that RMS $<50 \mu \mathrm{m}$ represents good congruency of two superimposed records (21). In this study, the RMS was lower than $50 \mu \mathrm{m}$ which met the requirements of congruency.

Interestingly, the increased volume of peri-implant soft tissue was observed within the short-term following definitive crown insertion in this study. According to the results of GI and BOP, the peri-implant soft tissue was in a healthy state. The possible reason for this is that the periimplant mucosa is affected by definitive crown insertion, causing a coronal shift in the peri-implant MM; however, this has not been fully supported by research. A previous study suggested that the abutment connection was a factor impacting peri-implant soft tissue changes $(8,22)$. There is therefore a need for further studies to be designed to verify these viewpoints. Moreover, based on our findings, significant differences were observed between weeks 1 and 2, and weeks 1 and 3 , while there was no significant difference between weeks 2 and 3, suggesting that mucosal changes resulting from crown insertion recovers within 2 weeks.

Among literatures evaluating peri-implant soft tissue changes after definitive crown insertion, Schneider et al. (6) and Bienz et al. (5) selected 1 week after crown insertion as baseline and performed soft tissue and bone augmentations in the implant process while Huber et al. (4) and Thoma et al. (3) selected 2 weeks after crown insertion as baseline and performed soft tissue augmentation in the implant process. In this study, 2 weeks after definitive crown insertion was selected as the baseline and soft tissue or bone augmentations were not involved. The result of baseline selection in this study is different from Schneider et al. (6) and Bienz et al. (5), while similar to Huber et al. (4) and Thoma et al. (3). These studies might have selected baseline based on clinical experience. The various baselines might affect peri-implant soft tissue change patterns after definitive crown insertion. From comparison between the four previous literatures and the current study, soft tissue and bone augmentations in the implant process might affect the baseline selection for evaluation of peri-implant soft tissue changes.

However, there were some limitations in this study. First, the sample size was small, and the follow-up was short. Second, only 3 time points and 1 implant system were involved in this study. Although these limitations exist, this study may still provide a reference for future clinicians.

\section{Conclusions}

Minimal peri-implant soft tissue changes occurred in this study. The time point of 2 weeks after definitive crown insertion was preliminarily selected as the baseline. Small sample size and few time points must be taken into consideration when interpreting our findings.

\section{Acknowledgments}

The authors would like to thank Yongqing Tao, dental technician in the Department of Prosthodontics, Peking University School and Hospital of Stomatology, for providing materials and techniques.

Funding: This study was supported by a grant from the National Program for Multidisciplinary Cooperative Treatment on Major Diseases (PKUSSNMP-202004 and PKUSSNMP-201901), and Peking University Clinical Scientist Program (BMU2019LCKXJ010).

\section{Footnote}

Reporting Checklist: The authors have completed the TREND reporting checklist. Available at https://dx.doi. org/10.21037/atm-21-3335

Data Sharing Statement: Available at https://dx.doi. org/10.21037/atm-21-3335

Conflicts of Interest: All authors have completed the ICMJE uniform disclosure form (available at https://dx.doi. org/10.21037/atm-21-3335). The authors have no conflicts of interest to declare.

Etbical Statement: The authors are accountable for all aspects of the work in ensuring that questions related to the accuracy or integrity of any part of the work are 
appropriately investigated and resolved. The study was conducted in accordance with the Declaration of Helsinki (as revised in 2013). The study was approved by the Biomedical Ethics Committee of Peking University School and Hospital of Stomatology, Beijing, China (ethical batch number: PKUSSIRB-201946083). Written informed consent was provided by all individuals included in the study.

Open Access Statement: This is an Open Access article distributed in accordance with the Creative Commons Attribution-NonCommercial-NoDerivs 4.0 International License (CC BY-NC-ND 4.0), which permits the noncommercial replication and distribution of the article with the strict proviso that no changes or edits are made and the original work is properly cited (including links to both the formal publication through the relevant DOI and the license). See: https://creativecommons.org/licenses/by-nc-nd/4.0/.

\section{References}

1. Sapata VM, Sanz-Martin I, Hammerle CHF, et al. Profilometric changes of peri-implant tissues over 5 years: A randomized controlled trial comparing a oneand two-piece implant system. Clin Oral Implants Res 2018;29:864-72.

2. Tian J, Wei D, Zhao Y, et al. Labial soft tissue contour dynamics following immediate implants and immediate provisionalization of single maxillary incisors: A 1-year prospective study. Clin Implant Dent Relat Res 2019;21:492-502.

3. Thoma DS, Gasser TJW, Jung RE, et al. Randomized controlled clinical trial comparing implant sites augmented with a volume-stable collagen matrix or an autogenous connective tissue graft: 3 -year data after insertion of reconstructions. J Clin Periodontol 2020;47:630-9.

4. Huber S, Zeltner M, Hämmerle CHF, et al. Noninterventional 1-year follow-up study of peri-implant soft tissues following previous soft tissue augmentation and crown insertion in single-tooth gaps. J Clin Periodontol 2018;45:504-12.

5. Bienz SP, Jung RE, Sapata VM, et al. Volumetric changes and peri-implant health at implant sites with or without soft tissue grafting in the esthetic zone, a retrospective case-control study with a 5 -year follow-up. Clin Oral Implants Res 2017;28:1459-65.

6. Schneider D, Grunder U, Ender A, et al. Volume gain and stability of peri-implant tissue following bone and soft tissue augmentation: 1-year results from a prospective cohort study. Clin Oral Implants Res 2011;22:28-37.

7. Bergendal B. When should we extract deciduous teeth and place implants in young individuals with tooth agenesis?. J Oral Rehabil 2008;35 Suppl 1:55-63.

8. Benic GI, Ge Y, Gallucci GO, et al. Guided bone regeneration and abutment connection augment the buccal soft tissue contour: 3 -year results of a prospective comparative clinical study. Clin Oral Implants Res 2017;28:219-25.

9. Fischer KR, Künzlberger A, Donos N, et al. Gingival biotype revisited-novel classification and assessment tool. Clin Oral Investig 2018;22:443-8.

10. Löe H. The Gingival Index, the Plaque Index and the Retention Index Systems. J Periodontol 1967;38:Suppl:610-6.

11. Roccuzzo M, Grasso G, Dalmasso P. Keratinized mucosa around implants in partially edentulous posterior mandible: 10-year results of a prospective comparative study. Clin Oral Implants Res 2016;27:491-6.

12. Heitz-Mayfield LJ. Peri-implant diseases: diagnosis and risk indicators. J Clin Periodontol 2008;35:292-304.

13. Cho SH, Schaefer O, Thompson GA, et al. Comparison of accuracy and reproducibility of casts made by digital and conventional methods. J Prosthet Dent 2015;113:310-5.

14. Chen L, Lin WS, Polido WD, et al. Accuracy, reproducibility, and dimensional stability of additively manufactured surgical templates. J Prosthet Dent 2019;122:309-14.

15. Schaefer O, Watts DC, Sigusch BW, et al. Marginal and internal fit of pressed lithium disilicate partial crowns in vitro: a three-dimensional analysis of accuracy and reproducibility. Dent Mater 2012;28:320-6.

16. Sanz Martin I, Benic GI, Hammerle CH, et al. Prospective randomized controlled clinical study comparing two dental implant types: volumetric soft tissue changes at 1 year of loading. Clin Oral Implants Res 2016;27:406-11.

17. Rojo E, Stroppa G, Sanz-Martin I, et al. Soft tissue volume gain around dental implants using autogenous subepithelial connective tissue grafts harvested from the lateral palate or tuberosity area. A randomized controlled clinical study. J Clin Periodontol 2018;45:495-503.

18. Michelinakis G, Apostolakis D, Tsagarakis A, et al. A comparison of accuracy of 3 intraoral scanners: A singleblinded in vitro study. J Prosthet Dent 2020;124:581-8.

19. Mennito AS, Evans ZP, Lauer AW, et al. Evaluation of the effect scan pattern has on the trueness and precision of six intraoral digital impression systems. J Esthet Restor Dent 
2018;30:113-8.

20. Fageeh HN, Meshni AA, Jamal HA, et al. The accuracy and reliability of digital measurements of gingival recession versus conventional methods. BMC Oral Health 2019;19:154.

21. Peters MC, Delong R, Pintado MR, et al. Comparison

Cite this article as: Zheng C, Wang S, Ye H, Liu Y, Hu W, Zhou Y. Baseline selection for evaluation of peri-implant soft tissue changes: a clinical trial. Ann Transl Med 2021;9(19):1494. doi: $10.21037 /$ atm-21-3335 of two measurement techniques for clinical wear. J Dent 1999;27:479-85.

22. Henriksson K, Jemt T. Measurements of soft tissue volume in association with single-implant restorations: a 1-year comparative study after abutment connection surgery. Clin Implant Dent Relat Res 2004;6:181-9. 